\title{
Title: Fatigue Crack Growth and Mechanical Behavior of Double-Edge-Cracked Ti/APC-2 Nanocomposite Laminates
}

\author{
Ming-Hwa Jen ${ }^{1}$, Li-Jen Hsu ${ }^{1}$, Yu-Cheng Liang ${ }^{1}$, and Ying-Hui Wu ${ }^{1}$ \\ ${ }^{1}$ National Sun Yat-sen University
}

August 11, 2020

\begin{abstract}
The mechanical properties and fatigue responses of double-edge-cracked Ti/APC-2 hybrid nano-composite laminates by tensile and cyclic tests were obtained. The double-edged cracks were cut with the crack lengths of $2.0 \mathrm{~mm}$ and $3.0 \mathrm{~mm}$ symmetrically and anti-symmetrically. The mechanical properties of symmetrically cracked samples are more detrimentally than those of anti-symmetrically counter parts. The greater the cracked angles, the greater the maximum load, however, the results of crack lengths were on the contrary. The fatigue life increased with the crack angle increasing, and also decreased with the crack length increasing. The enhancement of laminates by adding nano-powder did improve the fatigue life and maximum load, but not significantly. It is attributed to the local stress intensity factors at the crack tips mainly dominating the mechanical properties. Hence, the spreading of nano-power at the interface does not effectively strengthen the resistance to fatigue and fracture globally.
\end{abstract}

\section{NOMENCLATURE}

$a$ Crack length

$a^{*}$ The shortest distance between the midpoint of two cracks

$B$ Thickness of FMLs

$W$ Width of sample

$K_{I}$ Stress intensity factor of mode I

$K_{\text {II }}$ Stress intensity factor of mode II

$K_{C}$ Critical value of stress intensity factor of mixed mode

$K_{I}^{0}$ The revised results of stress intensity factor of mode I

$K_{\mathrm{II}}^{0}$ The revised results of stress intensity factor of mode II

$K_{e}$ Effective revised stress intensity factor range

$\vartheta$ Inclined angles

\section{INTRODUCTION}

Fiber metal laminates (FMLs) are hybrid composite structures constructed of thin sheets of metal alloys sandwiched by plies of fiber-reinforced polymeric composites. Considering the metal alloys as cover sheets. Jen et al. developed $\mathrm{Mg} / \mathrm{CF} / \mathrm{PEEK}$ nanocomposite laminates ${ }^{1}$ as well as Ti/CF/PEEK nanocomposite laminates ${ }^{2}$ and obtained their mechanical properties at elevated temperatures. AS-4/Polyether-etherketone (PEEK), called APC-2, thermoplastic composites were adopted, since PEEK polymer matrix can 
sustain its mechanical properties at temperatures up to $143^{\circ} \mathrm{C}^{3}$ and offers excellent toughness properties. FMLs with thermoplastic-based composites offer superior resistance to aggressive environments, outstanding interlaminar fracture properties, excellent resistance to both impact and cyclic loadings, short time to cure, ${ }^{4,5}$ and potentially wide applications. FMLs also exhibit excellent fatigue resistance and durability. The reduction of the crack growth rate in FMLs is caused by the bridging effect in the fiber layers ${ }^{6}$.

Kim et al. ${ }^{7}$ improved the fracture toughness of carbon black and nanoclay mixed with epoxy resin and measured the fracture toughness using the single edge notched bend specimens at the room $\left(25^{\circ} \mathrm{C}\right)$ and cryogenic $\left(-150^{\circ} \mathrm{C}\right)$ temperatures. Jen et al. ${ }^{8}$ developed a methodology to fabricate AS-4/PEEK aromatic polymer composite and nanocomposite laminates and found the optimal content of nanoparticles $\left(\mathrm{SiO}_{2}\right)$ was $1 \%$ by total weight. In fracture analysis the related famous theorems were proposed such as the maximum strain criterion by Chang ${ }^{9}$, and energy release rate criterion by Nuismer ${ }^{10}$. Hussain et al. ${ }^{11}$ investigated the mixed mode I and II cracking problem by using strain energy release rate concept. Ritchie et al. ${ }^{12}$ measured the effect of crack-tip shielding from the crack bridging effect for ARALL laminates. Asghar et al. ${ }^{13}$ studied the fatigue crack growth rate for CARALL, ARALL and GLARE composite laminates. Li and Johnson ${ }^{14}$ investigated the fatigue responses of hybrid titanium composite laminates. Cortes and Cantwell 15 obtained both tensile and fatigue properties of Ti/APC-2 hybrid laminates. Ilham et al. ${ }^{16}$ presented a summary of matrix cracking in nanocomposite materials under conditions of fatigue, tensile, thermal and flexural loadings. Borowski et al. ${ }^{17}$ reduced the interlaminar fiber-matrix cracking and delamination in CFRP laminates by adding the multi-walled carbon nanotubes to improve their fracture toughness. Mefford et al. ${ }^{18}$ investigated the scaling of the structural strength of polymer/graphene nanocomposites. The geometrically scaled single edge notch bending specimens with varying contents of graphene were tested at fracture and studied the effect of nanomodification on the scaling.

In the consideration of crack initiation, growth rate and direction, Gross and Seelig ${ }^{19}$ provided the methods in fracture mechanics to solve the problem of double-edge-cracked composite laminates subjected to tensile and cyclic loadings. Aliha et al. ${ }^{20}$ investigated the crack initiation behavior of different polyurethane foams under mixed modes such as I/II and I/III. The effect of specimen type, mode mixity and foam density was studied on fracture initiation angle and fracture trajectory. Wang et al. ${ }^{21}$ presented a theoretical and numerical study on the stress intensity factors for double-edge cracked steel plates strengthened with fiber reinforced polymer plates.

Guo and $\mathrm{Wu}^{22}$ presented a theoretical model to predict the fatigue crack growth rates in fiber-reinforced metal laminates that in good agreement with experimental data. Homan ${ }^{23}$ determined the fatigue initiation in fiber metal laminates by assuming that fatigue crack initiation in FMLs is determined only by the stress cycles in the metal layers. The validation fatigue tests showed that the assumptions proved to be correct. Alderliesten ${ }^{24}$ presented a new analytical model for constant-amplitude fatigue crack propagation of through cracks in fiber metal laminates Glare. The prediction model was implemented in a numerical program and was validated with a wide range of experimental data. Spronk, Sen and Alderliesten ${ }^{25}$ presented a methodology to predict the cycles to crack initiation in a notched FML due to cyclic loading. Gupta ${ }^{26}$ showed that the crack paths in FMLs under fatigue loading deflect because of the presence of mixed-mode loading at the crack tip. The amount of deflection depends on the mixed-mode ratio induced which, in turn depends on the Glare grade and the off-axis angle.

Herein, the Ti/APC-2 neat and nanocomposite laminates were fabricated. Then, the double-edge cracks were cut symmetrically and anti-symmetrically. From the tensile tests the load vs. displacement curves, maximum load, displacement and fracture mechanisms were received. From the base-line data of mechanical properties the cyclic tests were finished to obtain the load vs. cycles (P-N) curves, residual life and the mechanisms.

\section{EXPERIMENTAL}

12 inches wide Carbon-PEEK unidirectional prepregs (Cytec Industries Inc., USA) were cut and stacked into cross-ply [0/90] laminates. The Grade 1 (H: 0.015\%, O: 0.18\%, N: 0.03\%, Fe: 0.2\%, C: 0.08\%) Ti sheets, supplied by Kobe Steel, Ltd. (Japan), were $0.5 \mathrm{~mm}$ thick after rolling, heating, and flattening through scratch 
brushing. The ultimate tensile strength and modulus of elasticity of Ti are $330 \mathrm{MPa}$ and $83 \mathrm{GPa}$, respectively.

Prior to lamination, the slimmed Ti alloy sheets were pretreated to create a strong bonding with APC-2 prepregs. After a series of tensile tests, surface treatment with a chromic acid anodic method of electroplating was used. The thickness of the oxide coating film was approximately $40-80 \mathrm{~nm}$ through SEM. The composition of the coating was determined to contain $\mathrm{TiO}_{2}$ through EDS. The procedure of making nanoparticle solution was first to dilute nanoparticles in alcohol $\left(50 \mathrm{ml}\right.$ alcohol: $\left.2 \mathrm{~g} \mathrm{SiO}_{2}\right)$ and stirred uniformly. Then, $\mathrm{SiO}_{2}$ solution was spread on the prepregs, i.e., the interfaces of APC-2 laminate, in a temperature-controlled box to evaporate the alcohol.

The APC-2 prepregs were sandwiched between the Ti alloy sheets to form Ti/APC-2 hybrid three-layered laminate. A modified diaphragm curing process was adopted to cure the hybrid panel and the panel was cut into samples of 240 (length) $\times 25$ (width) $\times 1.55$ (thickness) $\mathrm{mm}^{3}$, as shown in Figure 1 . The samples were divided into 12 groups, including neat and nanocomposite laminates with two inclined crack lengths i.e. 2.0 $\mathrm{mm}$ and $3.0 \mathrm{~mm}$, at three angles such as $30^{\circ}, 45^{\circ}$ and $60^{\circ}$. The width of cracks was $0.3 \mathrm{~mm}$ according to ASTM E740-03.

An MTS-810 servohydraulic computer-controlled dynamic material testing machine was employed to conduct the tensile test and constant stress amplitude $\mathrm{T}-\mathrm{T}$ cyclic test with stress ratio $=0.1$, frequency $=5 \mathrm{~Hz}$, and a sinusoidal wave form under a load-controlled mode at room temperature. A 25-mm MTS-634.11 F-25 extensometer was used to continuously monitor the strain during the tests.

\section{RESULTS}

From the static tensile tests we received the load vs. displacement curves and the mechanical properties for neat and nanocomposite cracked samples of crack lengths $2.0 \mathrm{~mm}$ and $3.0 \mathrm{~mm}$ at inclined angles $\pm 30^{\circ}, \pm 45^{\circ}$, $\pm 60^{\circ}$. The data of 2.0 and $3.0 \mathrm{~mm}$ crack lengths were listed. For neat symmetrically double-edge-cracked samples the mechanical properties were presented in Table 1 for $\vartheta=30^{\circ}, \vartheta=45^{\circ}$, and $\vartheta=60^{\circ}$ and (a) for 2.0 $\mathrm{mm}$, (b) for $3.0 \mathrm{~mm}$ crack length, respectively. Similarly, the mechanical properties for crack length $2.0 \mathrm{~mm}$ are expressed in (a) and crack length $3.0 \mathrm{~mm}$ in (b) for Tables 2-4. Next, for nanocomposite symmetrically double-edge-cracked samples, their mechanical properties were presented in Table 2 for $\vartheta=30^{\circ}, \vartheta=45^{\circ}$, and $\vartheta=60^{\circ}$, respectively. As for neat anti-symmetrically double-edge-cracked samples the mechanical properties by tensile tests were listed in Table 3 for $\vartheta=30^{\circ}, \vartheta=45^{\circ}$, and $\vartheta=60^{\circ}$, respectively. As for nanocomposite anti-symmetrically double-edge-cracked samples the mechanical properties were presented in Table 4 for $\vartheta$ $= \pm 30^{\circ}, \vartheta= \pm 45^{\circ}$, and $\vartheta= \pm 60^{\circ}$, respectively.

From cyclic tests the P-N curves for neat symmetrically double-edge-cracked samples were shown in Figure 2 (a) for crack length $2.0 \mathrm{~mm}$ and (b) for crack length $3.0 \mathrm{~mm}$ with $\vartheta=30^{\circ}, 45^{\circ}, 60^{\circ}$ together. The P-N curves for nanocomposite symmetrically double-edge-cracked samples were presented in Figure 3(a) for crack length $2.0 \mathrm{~mm}$ and (b) for crack length $3.0 \mathrm{~mm}$ with $\vartheta=30^{\circ}, 45^{\circ}, 60^{\circ}$. Herein, the residual fatigue life is defined as the number of cycles due to applied loading that results in the broken sample with separated pieces. In the comparison of nano-powder $\mathrm{SiO}_{2}$ improvement, for example, both the P-N curves for neat and nanocomposite anti-symmetrically double-edge-cracked samples were illustrated in Figure 4 for crack length $3.0 \mathrm{~mm}$ at $\vartheta=$ $\pm 45^{\circ}$. The P-N curves for $2.0 \mathrm{~mm}$ and $3.0 \mathrm{~mm}$ crack lengths in nanocomposite anti-symmetrically doubleedge-cracked samples were represented in Figure 5 for $\vartheta= \pm 45^{\circ}$.

\section{DISCUSSION}

In fabricating Ti/APC-2 nanocomposite laminates the superior and stable mechanical properties of the samples due to tensile tests should be maintained. Based on the rule of mixtures it is found see that the errors were very small between the predicted results and experimental data, i.e., the errors for strength were less than $7.90 \%$, while the errors for stiffness less than $1.48 \%$. That demonstrates the fabricated neat and nanocomposite Ti/APC-2 samples were of good quality and small scatterness after cyclic tests, please refer to ${ }^{27}$.

Generally, it is reasonable to predict that the strength, stiffness and life of both neat and nanocomposite 
laminates, symmetrically and anti-symmetrically double-edge-cracked samples were lower for crack length $3.0 \mathrm{~mm}$ in the detrimental situations as illustrated in Tables 1(a) and 1(b) to 4(a) and 4(b). Similarly, the higher the inclined angles are, i.e., $\vartheta=60^{\circ}$ symmetric samples and $\vartheta= \pm 60^{\circ}$ for anti-symmetric samples, the higher the mechanical properties and fatigue lives are. That is attributed to the longer distance between the two crack tips. It is also found the mechanical properties of anti-symmetric samples are slightly better than those of symmetric counterparts. The shortest distance, i.e., show cut, between the two crack tips for the anti-symmetric samples is slightly longer than that of symmetric counterparts.

The addition of nano-powder $\mathrm{SiO}_{2}$ in the APC-2 interfaces did improve the mechanical properties and cyclic lives, but not significantly. The enhancement of mechanical properties and lives was less than $10 \%$. Some test data showed that the enhancement was even not occurred. It is reasonable to doubt that the enhancement at the crack tips was totally balanced by the crack tip stress intensity factors, i.e., the spreading of nano-powder was global; whilst the stress intensity factor as the crack tip was strongly a local point.

For symmetrically double-edge-cracked samples, as shown in Figure 1(b) and (c), the stress intensity factors, $K_{I}$ and $K_{\mathrm{II}}$, in mixed mode can be expressed in Equations 1-3, where $a$ is crack length, $W$ denotes the width of sample, and $B$ is thickness of FMLs. The critical value of SIF, $K_{C}$, is simply adopted in Equation 4.

$K_{I}=\frac{P}{B \sqrt{W}} f\left(\frac{a}{W}\right) \cos ^{2} \theta(1)$

$K_{\mathrm{II}}=\frac{P}{B \sqrt{W}} f\left(\frac{a}{W}\right) \varsigma \circ \sigma \vartheta \sigma \iota \nu \vartheta(2)$

where

$f\left(\frac{a}{W}\right)=\frac{\sqrt{\frac{\pi \alpha}{2 W}}}{2}$

english $\sqrt{1-\frac{a}{W}}\left[1.122-0.561\left(\frac{a}{W}\right)-0.205\left(\frac{a}{W}\right)^{2}+0.471\left(\frac{a}{W}\right)^{3}+0.190\left(\frac{a}{W}\right)^{4}\right](3)$

$K_{C}=\sqrt{K_{I}^{2}+K_{\mathrm{II}}^{2}}(4)$

Using Equations (1)-(4) the results of $K_{I}, K_{\mathrm{II}}$ and $K_{C}$ for two crack lengths at each inclined angle were easily obtained. In the consideration of the interaction of two crack tips of symmetrically double-edge-cracked samples the stress intensity factors should be corrected by Equations 5-6, where $a *$ is the shortest distance between the midpoint of two cracks. The revised forms are

$K_{I}^{0} \approx K_{I}\left[1+\frac{a^{*}}{2 d^{2}}(2 \cos 2 \varnothing-\cos 4 \varnothing)\right](5)$

$K_{\mathrm{II}}^{0} \approx K_{\mathrm{II}}\left[1+\frac{a^{*}}{2 d^{2}}(-\sin 2 \varnothing+\sin 4 \varnothing)\right](6)$

The results of stress intensity factors such as $K_{I}^{0}$ and $K_{\mathrm{II}}^{0}$ were listed in Table 5. Similarly, refer to Figure 1(b) the stress intensity factors can also be easily received for neat and nanocomposite anti-symmetrically double-edge-cracked samples of two crack lengths at each inclined angle. According the interaction of both crack tips as shown in Figure 1(c) the revised results of stress intensity factors such as $K_{I}^{0}$ and $K_{\mathrm{II}}^{0}$ for those samples can be calculated by using Equations 7-8, and the values are tabulated in Table 6, where $a^{*}=1.0$ $\mathrm{mm}$ for crack length $a=2.0 \mathrm{~mm}$ and $a^{*}=1.5 \mathrm{~mm}$ for $a=3.0 \mathrm{~mm}$.

$K_{I}^{0} \approx K_{I}\left[1+\frac{a^{* 2}}{2 d^{2}}(2 \cos 2 \varnothing-\cos 4 \varnothing)\right](7)$
$K_{\mathrm{II}}^{0} \approx K_{\mathrm{II}}\left[1+\frac{a^{* 2}}{2 d^{2}}(-\sin 2 \varnothing+\sin 4 \varnothing)\right](8)$

It is interesting to see for symmetrically double-edge-cracked samples the revised stress intensity factor $K_{I}^{0}$ decreases as the increasing of inclined angle, however, the revised $K_{\mathrm{II}}^{0}$ still keep the same value as $1.00 K_{\mathrm{II}}$, i.e., no change. As for anti-symmetrically double-edge-cracked samples both revised stress intensity factors, $K_{I}^{0}$ and $K_{\mathrm{II}}^{0}$, decrease as the increasing of inclined angle; whilst, $K_{I}^{0}$ reduces from $1.00160 K_{\mathrm{II}}$ for $a=2.0 \mathrm{~mm}$, 
and $1.00421 K_{I}$ for $a=3.0 \mathrm{~mm}$ at inclined angle $30^{\circ}$, i.e., $\backslash n K_{I}^{0}$ is over $1.0 K_{I}$ at $\vartheta=30^{\circ}$, down to $0.99954 K_{I}$ for $a=2.0 \mathrm{~mm}$ and $0.99890 K_{I}$ for a $=3.0 \mathrm{~mm}$ at $\vartheta=60^{\circ}$, i.e., $K_{I}^{0}$ is lower than $1.0 K_{I}$.

Based on the suitable methodology to predict crack growth rate and life the well-known Paris Law has to be modified. In the mixed mode fracture the effective revised stress intensity factor range, $K_{e}$, instead of $K_{I}^{0}$ and $K_{\mathrm{II}}^{0}$, the hybrid FMLs material properties and mechanical behavior, and most importantly the fracture process and mechanisms need be involved.

The surprising and interesting phenomenon is the occurrence of a small broken ellipse at the center part when both side crack tips grow towards each other along the shortest path to deviate slightly and do not coalesce. Due to their interaction, both crack tips run around each other in a certain distance until, at some later instant, each of them merges with the other crack. The failure mechanisms of nanocomposite symmetrically double-edge-cracked samples due to cyclic loading were shown in Figure 6(a) the enlarged scheme and Figure 6 (b) the photo of failed sample. Similarly, the failure mechanisms of nanocomposite antisymmetrically double-edge-cracked samples due to cyclic loading were presented in Figure 7(a) the enlarged scheme and Figure 7(b) the photos of three failed samples.

From on the above-mentioned the particular failure mechanisms such as the small elliptical pieces formed at failure in both kinds of FMLs that the irregular crack growth rate and path make the fatigue life prediction a very complicated task.

\section{CONCLUSION}

The neat and nanocomposite Ti/APC-2 hybrid laminates were fabricated. Two types of symmetrical and anti-symmetrical double-edge-cracked specimens were made. The crack lengths were $2.0 \mathrm{~mm}$ and $3.0 \mathrm{~mm}$ and inclined angles $\vartheta=30^{\circ}, 45^{\circ}$, and $60^{\circ}$ for symmetric samples and $\vartheta= \pm 30^{\circ}, \pm 45^{\circ}$, and $\pm 60^{\circ}$ for anti-symmetric samples. All the specimens were subjected to tensile tests and cyclic tests separately to obtain the loaddisplacement curves and the mechanical properties, and the P-N curves and fatigue lives, respectively.

The longer the crack lengths are, the lower the properties and lives are. Similarly, the higher the inclined angles are, the lower the properties and live are. The enhancement of adding nano-powder did improve the mechanical properties, but not significantly. The mechanical properties and fatigue lives are better for anti-symmetric samples than those of symmetric samples. The failure mechanisms of small elliptical broken pieces were found due to cyclic loading for both kinds of FMLs.

\section{ACKNOWLEDGEMENTS}

The authors would like to gratefully acknowledge the sponsorship from the Ministry of Science and Technology under the project number: MOST 107-2221-E-110-051.

\section{REFERENCES}

1. Jen MHR, Tseng YC, Li PY. Fatigue response of hybrid magnesium/carbon-fiber/PEEK nanocomposite laminates at elevated temperature. J Jpn Soc Exp Mech . 2007;7: s56-s60.

2. Jen MHR, Chang CK, Sung YC. Fabrication and mechanical properties of Ti/APC-2 hybrid nanocomposite laminates at elevated temperatures.J Compos Mater . 2015;50: 2035-2045.

3. Unger WJ, Hansen JS. The Effect of Thermal-Processing on Residual Strain Development in Unidirectional Graphite Fiber Reinforced Peek.J Compos Mater . 1993;27: 59-82.

4. Abdullah MR, Cantwell WJ. The impact resistance of polypropylene-based fibre-metal laminates. Compos Sci Technol . 2006;66: 1682-1693.

5. Villanueva GR. Processing and characterisation of the mechanical properties of novel fibre-metal laminates. PhD. dissertation, University of Liverpool; 2002.

6. Sinke J. Development of Fibre Metal Laminates: concurrent multi-scale modeling and testing. $J$ Mater Sci . 2006;41: 6777-6788.

7. Kim BC, Park SW, Lee DG. Fracture toughness of the nano-particle reinforced epoxy composite. Compos Struct . 2008;86: 69-77. 
8. Jen MHR, Tseng YC, Wu CH. Manufacturing and mechanical response of nanocomposite laminates. Compos Sci Technol . 2005;65: 775-779.

9. Chang KJ. On the Maximum Strain Criterion-A New Approach to the Angled Crack Problem. Eng Fract Mech . 1981;14: 107-124.

10. Nuismer RJ. An Energy Release Rate Criterion for Mixed Mode Fracture.Int J Fract . 1975;11: 245-250.

11. Hussain MA, Pu SL, Underwood J. Strain Energy Release Rate for a Crack under Combined Mode I and II. Fracture analysis ASTM STP 560. American Society for Testing and Materials, Philadelphia. $2-28 ; 1974$.

12. Ritchie RO, Yu W, Bucci RJ. Fatigue Crack Propagation in ARALL Laminates: Measurement of the Effect of Crack-tip Shielding from Crack Bridging, Eng Fract Mech . 1989;32: 361-377.

13. Asghar A, Nasir MA, Qayyum F, Shah M, Azeem M, Nauman S, Khushnood S. Investigation of fatigue crack growth rate in CARALL, ARALL and GLARE. Fatigue Fract Eng Mater Struct . 2017;40: 10861100.

14. Li E, Johnson WS. An investigation into fatigue of a hybrid titanium composite laminate. J Comp Technol Res . 1998;20: 3-12.

15. Corte's P, Cantwell WJ. The tensile and fatigue properties of carbon fiber-reinforced PEEK-titanium fiber-metal laminates. J Reinf Plast Compos . 2004;23: 1615-1623.

16. Muhammad Ilham K, Anuar H, Norhashimah MS, Idris Yaacob I, Sapuan SM. Matrix Cracking in Reinforced Polymer Nanocomposites: A Review.J Adv Rev Sci Res . 2015;11: 13-36.

17. Borowski E, Soliman E, Kandi UF, Taha MR. Interlaminar Fracture Toughness of CFRP Laminates Incorporating Multi-Walled Carbon Nanotubes. Polymer . 2015;7: 1020-1045.

18. Mefford CH, Qiao Y, Salviato M. Failure Behavior and Scaling of Graphene Nanocomposites. Compos Struct . 2017;176: 961-972.

19. Gross D, Seelig T. Fracture Mechanics: With an Introduction to Micromechanics, first ed. Berlin Heidelberg, Germany: Springer-Verlag: 2006.

20. Aliha MRM, Mousavi SS, Bahmani A, Linul E, Marsavina L. Crack Initiation Angles and Propagation Paths in Polyurethane Foams under Mixed Mode I/II and I/III Loading. Theor Appl Fract Mech . 2019;101: 152-161.

21. Wang HT, Wu G, Pang YY. Theoretical and Numerical Study on Stress Intensity Factors for FRPStrengthened Steel Plates with Double-Edged Cracks. Sensor. 2018;18: E2356.

22. Guo YJ, Wu XR. A Theoretical Model for Predicting Fatigue Crack Growth Rates in Fiber-Reinforced Metal Laminates. Fatigue Fract Eng Mater Struct . 1998;21: 1133-1145.

23. Homan JJ. Fatigue Initiation in Fiber Metal Laminates. Int J Fatigue . 2006;28: 366-374.

24. Alderliesten RC. Analytical Prediction Model for Fatigue Crack Propagation and Delamination Growth in Glare. Int J Fatigue . 2007;29: 628-646.

25. Spronk SWF, Şen I, Alderliesten RC. Predicting Fatigue Crack Initiation in Fiber Metal Laminates Based on Metal Fatigue Test Data,Int. J Fatigue . 2015;70: 428-439.

26. Gupta M. Directionality of Damage Growth in Fiber Metal Laminates and Hybrid Structures. PhD Thesis, E.T.S.I.A. Universi dad Polytechnico de Madrid; 2015.

27. Jen MHR, Kuo GT, Wu YH, Chen YJ. Fatigue Responses of Cracked Ti/APC-2 Nanocomposite Laminates at Elevated Temperature, J Compos Mater . 2019;54: 1705-1715.

\section{Hosted file}

2020.08.10--manuscript-table-1-final.docx available at https://authorea.com/users/349917/ articles/474896-title-fatigue-crack-growth-and-mechanical-behavior-of-double-edgecracked-ti-apc-2-nanocomposite-laminates

\section{Hosted file}

2020.08.10--manuscript-table-2-final.docx available at https://authorea.com/users/349917/ articles/474896-title-fatigue-crack-growth-and-mechanical-behavior-of-double-edge-

cracked-ti-apc-2-nanocomposite-laminates 


\section{Hosted file}

2020.08.10--manuscript-table-3-final.docx available at https://authorea.com/users/349917/ articles/474896-title-fatigue-crack-growth-and-mechanical-behavior-of-double-edgecracked-ti-apc-2-nanocomposite-laminates

\section{Hosted file}

2020.08.10--manuscript-table-4-final.docx available at https://authorea.com/users/349917/ articles/474896-title-fatigue-crack-growth-and-mechanical-behavior-of-double-edgecracked-ti-apc-2-nanocomposite-laminates

\section{Hosted file}

2020.08.10--manuscript-table-5-final.docx available at https://authorea.com/users/349917/ articles/474896-title-fatigue-crack-growth-and-mechanical-behavior-of-double-edgecracked-ti-apc-2-nanocomposite-laminates

\section{Hosted file}

2020.08.10--manuscript-table-6-final.docx available at https://authorea.com/users/349917/ articles/474896-title-fatigue-crack-growth-and-mechanical-behavior-of-double-edgecracked-ti-apc-2-nanocomposite-laminates

\section{Hosted file}

2020.08.10--manuscript-figure-1-final.docx available at https://authorea.com/users/349917/ articles/474896-title-fatigue-crack-growth-and-mechanical-behavior-of-double-edgecracked-ti-apc-2-nanocomposite-laminates

\section{Hosted file}

2020.08.10--manuscript-figure-2-final.docx available at https://authorea.com/users/349917/ articles/474896-title-fatigue-crack-growth-and-mechanical-behavior-of-double-edgecracked-ti-apc-2-nanocomposite-laminates

\section{Hosted file}

2020.08.10--manuscript-figure-3-final.docx available at https://authorea.com/users/349917/ articles/474896-title-fatigue-crack-growth-and-mechanical-behavior-of-double-edgecracked-ti-apc-2-nanocomposite-laminates

\section{Hosted file}

2020.08.10--manuscript-figure-4-final.docx available at https://authorea.com/users/349917/ articles/474896-title-fatigue-crack-growth-and-mechanical-behavior-of-double-edgecracked-ti-apc-2-nanocomposite-laminates

\section{Hosted file}

2020.08.10--manuscript-figure-5-final.docx available at https://authorea.com/users/349917/ articles/474896-title-fatigue-crack-growth-and-mechanical-behavior-of-double-edgecracked-ti-apc-2-nanocomposite-laminates

\section{Hosted file}

2020.08.10--manuscript-figure-6-final.docx available at https://authorea.com/users/349917/ articles/474896-title-fatigue-crack-growth-and-mechanical-behavior-of-double-edgecracked-ti-apc-2-nanocomposite-laminates

\section{Hosted file}


2020.08.10--manuscript-figure-7-final.docx available at https://authorea.com/users/349917/ articles/474896-title-fatigue-crack-growth-and-mechanical-behavior-of-double-edgecracked-ti-apc-2-nanocomposite-laminates 